\title{
Pintura, literatura, arte: alguns diálogos na poesia de Murilo Mendes
}

Bernardo Nascimento de Amorim Universidade Federal de Minas Gerais

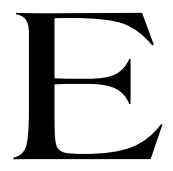

m uma passagem do livro em prosa O discípulo de Emaús, escrito por Murilo Mendes em 1945, entramos em contato com uma de suas afirmações a respeito do que seja a poesia. O escritor manifesta-se então com as seguintes palavras: "Viver a poesia é muito mais necessário do que escrevê-la". ${ }^{1}$ A contundente afirmativa, que de modo algum diminui a importância do trabalho de construção estética, deixa-nos entrever a porta de entrada para os fecundos contatos que a obra do poeta manteve, durante toda a sua trajetória, com as mais diversas manifestações artísticas. Entendendo como poesia algo existente de fato no mundo, antes mesmo de concretizar-se em uma obra, Murilo preconiza um alargamento do campo do poético, que se torna capaz de abarcar não só o gênero da literatura designado como poesia lírica, mas toda a manifestação de uma experiência subjetiva transformadora da matéria bruta do real, que descortina os aspectos invisíveis subjacentes ao universo do concreto. A poesia estaria ligada, em sentido amplo, no contexto de uma perspectiva existencial, à própria capacidade do homem de dedicarse a uma tentativa de ordenação do caos, em um percurso cujo horizonte seria a transcendência da ordem aparente do mundo. A arte surge como uma experiência vital capaz de propiciar a expansão da consciência, a elevação do espírito e a transfiguração da vida humana, no seio de um projeto estético no qual se abraça a possibilidade de uma percepção visionária, diluidora das fronteiras entre o concreto e o sobrenatural.

${ }^{1}$ MENDES, 1994. p. 843. 
Murilo esteve, o tempo todo, voltado para a capacidade produtiva das manifestações do espírito humano, em seu permanente fluxo entre o real e as potências transfiguradoras. Uma poética inteiramente aberta ao mundo das formas, disposta a consolidar espaços de encontro, implicaria o diálogo constante e produtivo com o universo de todas as outras artes, em especial aquelas cujo material essencial de trabalho seria a própria imagem. Não por acaso, esta assume, na poesia do autor, um lugar de destaque. Enquanto meio de reunião de contrários, interligados por um princípio de identidade, a imagem permite ao poeta a estruturação de poemas em que há espaço para a convergência do que diverge. A ânsia da harmonia, o impulso ordenador, tem que lidar o tempo todo com a força da dissonância. Entre o rigor e a simetria interpõe-se a energia liberada do contato entre planos opostos, levados a se fundirem. ${ }^{2} \mathrm{~A}$ proeminência do elemento plástico na obra do escritor mostra-se a todo momento marcante, ainda que alterações aconteçam no que diz respeito ao modo como aparece. A visualidade assumiria um papel central, em uma poesia que comporta como poucas o atributo de imagética, uma poética que muitas vezes deixa em segundo plano o que se restringiria ao âmbito da mensagem, de um discurso estritamente lógico e comunicativo. A visão se constitui como um dos mais potentes instrumentos da percepção poética, a partir da qual se pode impulsionar o contato entre a realidade sensível e a fantasia, o mundo do concreto e o imaginário.

Em toda a sua trajetória como poeta, Murilo buscou nas artes plásticas, entre os seus pintores prediletos, tanto modelos visuais, um repertório de imagens, quanto elementos de estruturação das composições. Os procedimentos diversos de uma arte combinatória, baseada no impulso de aproximar realidades distintas, conformando um novo universo, tais como a fotomontagem e a colagem, ou a técnica concisa e disciplinada da forma, serviriam ao projeto poético do escritor, atento a todo o processo de construção que viesse a possibilitar a libertação da arte de uma necessidade de mera reprodução ou interpretação do real.

No percurso poético de Murilo, percebe-se nitidamente uma diferença entre os seus primeiros livros e os últimos, fato que se evidencia

\footnotetext{
${ }^{2}$ No campo da lírica, a imagem viria a ser, nas palavras de Antônio Cândido, uma forma de "reordenação do mundo segundo a lógica poética" (Cf. CÂNDIDO, 1993. p. 89).
} 
de modo claro quando se observam os modos de estruturação dos poemas. Embora o projeto do autor tenha se mantido o mesmo em suas bases essenciais, a sua poesia passa por modificações que, significativamente, dialogam com os movimentos internacionais das artes plásticas. Notam-se dois espaços mais amplos de afinidades, que se comunicam e acrescentam sempre novos elementos a uma poética afeita a recusar qualquer estancamento. A proximidade com os surrealistas diria respeito a alguns traços da própria natureza da poesia de Murilo que, equilibrada entre o místico e o cotidiano, entre o mágico e o concreto, estaria sempre pronta a reorganizar o universo em uma nova ordem de significação, desejosa de ultrapassar o real. Em um primeiro momento, a poesia do autor mostra-se penetrada pela vontade de exploração de estados subjetivos, alimentados por uma fantasia que bordeja o rompimento de quaisquer limites. Por outro lado, a associação à arte construtivista, proeminente em uma segunda fase da poesia do autor, implicaria uma guinada em direção a um maior rigor, quando a disciplina parece se sobrepor à fantasia e a simetria procura mais insistentemente tomar o lugar da dissonância. Neste momento, evidencia-se uma maior valorização do equilíbrio, da harmonia nas estruturas, sejam pictóricas ou poéticas. Privilegia-se então um tratamento sobretudo objetivo da matéria do poema. $^{3}$

Tal como entre os surrealistas, representantes de uma corrente ainda alimentada por uma certa visão de mundo em que há lugar para a utopia e a revolução, a poética de Murilo esteve fundamentada em uma postura de recusa diante dos valores da sociedade de seu tempo. Acreditava-se na arte como um instrumento de cognição e como meio de participação na transformação social. Tinha-se em mente a subversão da ordem mais restrita do mundo, a partir de um rearranjo original de elementos diversos, da expansão de novos processos e do uso de novos materiais. Afim aos recursos técnicos empregados pelos artistas afiliados ao movimento, o autor explora a fundo os desdobramentos da justaposição da imagem, da

\footnotetext{
${ }^{3}$ Quando dizemos arte construtivista, ou construtivismo, estamos nos referindo, de modo amplo e genérico, às tendências intelectuais e geométricas, regidas por uma vontade de disciplina e pela busca da forma pura, surgidas nas artes plásticas, sob diversos nomes (suprematismo, não-objetivismo, neoplasticismo), por volta de 1913.
} 
interpenetração dos planos, modos capazes de promover a criação de universos insólitos. No acoplamento de elementos díspares, na criação de atmosferas oníricas, desarticulam-se os dados objetivos da realidade. Murilo, de um modo singular entre os poetas brasileiros, desenvolve uma poética em que recebe lugar de destaque a reunião, como que arbitrária, de elementos tradicionalmente inconciliáveis. Em um mesmo espaço, convivem, tocados por uma nova harmonia, em uma atmosfera mágica e enigmática, o cotidiano e o maravilhoso, o natural e o sobrenatural, o real e o sonho. Desde o primeiro livro do poeta, publicado em 1930, notase de fato a influência do movimento surrealista francês, importante não só como um manancial onde se buscar referências, mas como um exemplo de uma concepção de arte muito próxima daquela que irá informar a produção do autor. Impulsionar uma expressão estética cujo elemento fundamental fosse a criação, experiência capaz de descortinar novas formas de realidade, ambicionando abarcar a totalidade de um mundo apreendido em um movimento de transfiguração, seriam as bases tanto da atitude surrealista quanto da poética de Murilo.

Se aceitarmos a divisão do percurso do escritor entre duas grande fases, uma primeira marcada não só pelo surrealismo, como também pela antropofagia, e uma segunda mais próxima das experiências do construtivismo, de fato poderemos observar algumas relevantes diferenças, em particular, quanto ao modo como acontece o diálogo e a apropriação dos elementos das artes plásticas na escrita do poeta. Em um primeiro momento, o de poemas como Saudaçâo a Ismael Nery e Glória de Cícero Dias, em que a estrutura dos versos guarda uma profunda ligação com a estética surrealista, impregnada do raciocínio da colagem, alguns artistas são tomados como referência para a criação de um universo que reproduz a atmosfera dos quadros dos pintores, elencando uma série dos traços constantes em suas obras. Neste sentido, o poema que homenageia o pintor Cícero Dias seria uma narrativa que situa o homenageado em um quadro cujo ambiente é o mesmo de suas telas, com querubins, estrelas, dançarinas de café barato, banda de músicos e meninas convencidas ${ }^{4}$, como a flutuar em um espaço sem limites definidos. O cotidiano mistura-se ao celeste, quando os elementos prosaicos do quadro comunicam o sinal da glória destinada ao artista. Do

\footnotetext{
${ }^{4}$ MENDES, 1994. p. 101.
} 
mesmo modo, mas indo um pouco além, nos versos da Saudação, realizase uma reunião de objetos e impulsos que alimentariam as obras de Ismael. O mundo das formas, entre os cubos verdes e as esferas azuis, de onde se pode fixar os contornos dos corpos, seria informado pela iluminação transcendente do sopro do espírito da vida, que faria o artista pensar desligado do tempo, penetrando o sentido das idéias, das cores, a totalidade da Criação. À observação da natureza do processo criativo do pintor acrescenta-se uma espécie de interpretação afetiva do conjunto de sua pintura, vista como capaz de reunir as partes desconbecidas do mundo, os ritmos movendo as figuras humanas, em uma síntese de forma e transparência. ${ }^{5}$ Desde logo, se evidencia o caráter de identificação do poeta com os pintores com quem dialoga, uma vez que os elementos enumerados ou a interpretação da obra do artista em questão acabam por fornecer indícios dos movimentos da própria poesia de Murilo. Em Vermeer de Delft, composição já de Poesia Liberdade, o poema torna-se espaço para uma síntese dos temas e imagens presentes na obra do pintor holandês, observados a partir de um olhar que não exclui a emoção do poeta (através dos seus cristais / restitui a inocência) ${ }^{6}$, contemplador da obra. O diálogo estabelecido continua a ser a tentativa de recriação de um universo plástico a partir da enumeração dos motivos da pintura. O poema demonstra, no entanto, na sua concisão, não mais a expansão característica da identificação com os citados pintores brasileiros do primeiro livro, mas os sinais de uma impregnação da vontade de equilíbrio e economia.

Em Tempo espanbol, por sua vez, já agora no seio do que seria a segunda fase da produção de Murilo, destacam-se os vários poemas dedicados a pintores. A experiência do contato com a Espanha dá-se sobretudo enquanto encontro com as manifestações das criações do espírito, a poesia em sentido amplo, sejam as obras da arquitetura, da literatura ou da pintura. O livro dá início a uma maior impregnação de uma postura distanciada na contemplação dos objetos de arte, quando a expressão dos estados subjetivos torna-se menos expansiva. Surge um viés mais crítico, uma perspectiva predominantemente analítica das obras. A abertura ao construtivismo, que se coaduna às transformações na poética

\footnotetext{
${ }^{5}$ MENDES, 1994. p. 115.

${ }^{6}$ MENDES, 1994. p. 406.
} 
do autor, não impede, no entanto, a fruição estética e a transformação em poesia da pintura de artistas de estilos e períodos distintos, desde El Greco e Goya até Miró e Picasso. Em alguns momentos, do mesmo modo como a imagem surrealista e a colagem haviam sido tipos de raciocínio trazidos para a composição do poema, desdobra-se o diálogo produtivo com os processos da criação pictórica das obras. O caso de Juan Gris é, neste sentido, exemplar:

Espanha, mestra do espaço,

Deu a pureza, medida

$\mathrm{Na}$ área total da pintura

Com o gênio da concisão,

Pelo pincel de Juan Gris.

Nessa pintura pensada

Com clareza dialética,

Espanha, dita "irracional",

Pelos planos de Juan Gris

Mostra o acordo e a simetria. ${ }^{7}$

Diante da composição, verifica-se logo o cuidado com a economia da forma, a procura de conceber o poema a partir do mesmo acordo $e$ simetria que, na concepção de Murilo, caracterizariam a pintura do artista espanhol. As duas estrofes apresentam ambas o mesmo número de versos, cinco, todos com a mesma medida, sete sílabas. O apuro formal direcionase no sentido de assemelhar-se ao trabalho do artista plástico, que diante do espaço em princípio caótico, irracional, criaria uma pureza concisa, equilibrada. Conjugam-se no poema dois dos movimentos do poeta frente a uma pintura. Por um lado, tem-se uma interpretação dos princípios de composição do pintor. Por outro, assimilam-se os processos típicos da construção do artista na própria disposição dos versos. A postura crítica do poeta em relação ao objeto artístico permite a sua decantação, a análise e a apropriação daqueles que seriam alguns dos elementos essenciais da pintura de Juan Gris.

Em seu último livro de poemas publicado em vida, Murilo nos expõe ainda a sua relação com a obra do iniciador do suprematismo,

7 MENDES, 1994. p. 617. 
revelando a sua abertura e o seu conhecimento dos processos fundamentais por que passara a arte moderna em seu percurso ao longo do século. ${ }^{8}$ Kasimir Malevitch é observado a partir de traços de sua própria criação, ora uma paisagem de cilindros $\&$ triângulos, ora um simples quadrado negro em campo branco. A avaliação da obra do artista, tal como em uma análise crítica, concentra-se no final do poema, revelando atributos que acabam por dizer respeito também às ambições da própria poesia de Murilo: Ajustam-se antagonismos / Na calma dinâmica visivel. ${ }^{9}$ Diante do rigor da abstração geométrica, percebe-se mais uma vez a substância essencial da poética do autor, o que representa a continuidade do seu projeto, sempre destinado a lidar com o múltiplo, o heteróclito, mas em uma tentativa de ordenação.

Convergência, escrito entre 1963 e 1966, o livro no qual se encontra o poema acima mencionado, mostra-se impregnado de um espírito que demonstra em muitos momentos a ligação do poeta com as correntes estéticas mais contemporâneas. A capacidade do escritor de compreensão e apropriação dos movimentos dinâmicos das artes, em suas mais diversas manifestações, revela-se um traço mesmo de sua experiência estética. Muitas vezes, os poemas lembram as inovações concretistas, inseridas de modo polêmico na história então recente da literatura brasileira. Sem se chegar ao radicalismo do abandono do verso, exploram-se os espaços da página, inusitados sinais ortográficos e a maleabilidade do significante. A metalinguagem se faz presente, como um sintoma das preocupações do poeta em fazer da criação também uma matéria de reflexão. A poesia torna-se tema sobre o qual o escritor discorre, revelando poeticamente os motivos de sua obra e o seu próprio sentimento em relação à prática poética. A abordagem torna-se, algumas vezes, sistemática e direta, a partir das questões que o escritor considera em torno de seu próprio fazer: $O$ poema é o texto? Opoeta? / O poema é o texto + o poeta? / O poema é o poeta - o texto? ${ }^{10}$

\footnotetext{
${ }^{8} \mathrm{O}$ suprematismo teria sido de fato o primeiro movimento a tomar por base as formas geométricas exatas, sem qualquer preocupação de representação (Cf. DICIONÁRIO, 1981. p. 330-331).

${ }^{9}$ MENDES, 1994. p. 658, 659.

${ }^{10}$ MENDES, 1994. p. 737-740.
} 
Em Convergência, Murilo coloca-se como um atento observador da obra alheia, em um processo que permite a transfiguração do objeto contemplado em matéria de poesia. A apreciação dos artistas configurase ao mesmo tempo como uma homenagem, uma avaliação crítica e um olhar que visa a sua situação histórica. O livro apresenta uma extensa relação dos contatos estabelecidos pelo poeta no campo das artes. Murilogramas e grafitos compõem o que seria um paideuma do autor, a listagem, em modo ao mesmo tempo poético e crítico, de muitas de suas referências mais importantes, fontes de permanentes diálogos e encontros. O conjunto das composições acaba por conformar um corpus, apresentado em áreas de afinidade lucidamente compartimentadas. Os poemas dispõem-se de modo que a sua reunião em seqüência cria grupos de autores. Baudelaire é situado ao lado de Rimbaud e Mallarmé. Bandeira encontra-se próximo a Oswald, Graciliano, Drummond e João Cabral. No exemplar Grafito segundo Kafka, a caracterização de uma poética, entremeada a uma personalidade, conjuga-se a uma postura de absorção de perspectivas, em um processo que dilui os limites da diferença entre o poeta e o seu objeto. Na tentativa de estabelecimento do diálogo, Murilo encena a sua própria voz, direcionada ao interlocutor (Que tinhas em comum contigo mesmo? / Bastava-te o respiro da palavra), e a do outro, como se este falasse através dos versos: Não pedi para nascer, não escolhi meus pais. / Fui imposto a mim próprio. O enigma permanece. ${ }^{11} \mathrm{~A}$ identificação, o compartilhar uma mesma postura diante do mundo, fazse o princípio sobre o qual se assenta o encontro com a esfera da arte e dos artistas, um espaço em que a poesia, em sentido amplo, é um modo de percepção mais aguda dos fenômenos do universo.

No último momento de sua obra, Murilo parece intensificar os movimentos da reflexão e da análise, fazendo delas as diretrizes para a composição de seus poemas, transformados em espaços privilegiados de contato. Uma maior dose de objetividade passa a habitar o corpo do poema, capaz de incorporar, em um permanente processo de aprendizagem, as lições tanto dos antigos quanto dos mais novos mestres. Os poemas feitos homenagem mostram-se como uma conjugação entre a busca de traços próprios dos artistas de quem se trata e as invenções experimentais de linguagem, reveladoras da necessidade do poeta de

${ }^{11}$ MENDES, 1994. p. 647-650. 
acompanhar o seu tempo. A literatura e as outras artes são tomadas como objetos, sobre os quais se debruça um impulso ordenador, ao que não deixa de se aliar, no entanto, a sempre imprescindível invenção de linguagem. No diálogo com outros escritores, e artistas em geral, apresentam-se inseparáveis a apreciação crítica e a invenção poética. O princípio da reunião insólita dos contrários, que presidia uma invenção de traços surrealistas, mostra-se agora mais contido, mas ainda de certo modo presente, enquanto vontade de fazer da poesia um terreno propício para a convivência dos mais diferentes tempos e espaços.

O gosto pela forma, sejam as pictóricas ou aquelas que se desdobram no espaço da palavra, teria permitido desde sempre a familiaridade de Murilo com os mais diversos movimentos das artes, o diálogo com os artistas e o entendimento de seus processos de criação. $\mathrm{Na}$ literatura e na pintura, em especial, o poeta teria encontrado terrenos com os quais foi possível a comunicação e o aprendizado, de onde assimilar continuamente novas formas de construção artística e realização poética. A literatura diria respeito ao próprio campo que o autor escolhera para exercitar o seu pendor para a poesia. As artes plásticas, espaço privilegiado para o exercício da percepção visual, carregaria em sua essência a produção da imagem, meio através do qual o mundo revela, em matéria forjada pelo espírito, a sua natureza poética. Assumindo a atitude de quem desconfia da ordem existente, imaginando e acreditando na potencialidade de uma nova organização ou ordenação dos elementos constituintes daquilo que se apresenta ao comum dos sentidos, Murilo esteve sempre atento à poesia que existe no mundo, em toda a possibilidade de transfiguração da realidade. O poeta deixa-nos uma obra perpassada o tempo todo, como poucas, pelo diálogo com as outras artes, em uma poética que não se restringe a uma corrente ou tendência estética única, mas antes assume uma postura antropofágica, em que elementos diversos dão origem a uma obra singular. A inspiração, os modelos e mesmo as técnicas fazem parte de um espaço de identificação, de afinidade com aquilo que habitaria todos aqueles que fazem da poesia um modo de existência, base sobre a qual se assentam as diferentes, mas convergentes, perspectivas e olhares sobre o mundo, a vida e a própria arte. 


\section{Referências Bibliográficas}

ARRIGUCCI JR., Davi. O cacto e as ruinas: a poesia entre outras artes. São Paulo: Duas Cidades, 1997. p. 79-99.

CÂNDIDO, Antônio. O estudo analítico do poema. São Paulo: FFLCH-USP, 1993. (Terceira leitura, 2). 103 p.

CARVALHO, Raimundo Nonato Barbosa de. Murilo Mendes: o olhar vertical. 1993. 101 f. Dissertação (Mestrado em Literatura Brasileira) - Faculdade de Letras, Universidade Federal de Minas Gerais, Belo Horizonte.

DAIBERT, Arlindo. Arte e literatura. In: . Caderno de escritos. Rio de Janeiro: Sette Letras, 1995. p. 86-111.

DICIONÁRIO da pintura moderna. São Paulo: Hemus, 1981. p. 11-14; 29-30; 330-331.

GUIMARÃES, Júlio Castañon (Org.). Murilo Mendes: 1901-2001. Juiz de Fora: CEMM / UFJF, 2001. 168 p.

MENDES, Murilo. Poesia completa e prosa. Rio de Janeiro: Nova Aguilar, 1994. $1784 \mathrm{p}$.

MOURA, Murilo Marcondes de. Pressupostos básicos. In: . A poesia como totalidade. São Paulo: Editora da Universidade de São Paulo; Giordano, 1995. p. 13-65. 


\section{Resumo}

A partir de uma compreensão da poesia como algo que existe no mundo, e não só no corpo do poema, Murilo Mendes foi capaz de expandir o alcance de sua experimentação estética, abarcando manifestações, formas e perspectivas de diversos tipos de arte. Este trabalho visa analisar algumas das relações significativas entre a obra do poeta - em especial a sua obra poética -, a pintura e a literatura, a partir dos contatos em que Murilo, por um lado, estabelece as suas principais referências, e por outro, se apropria de procedimentos diversos, tornando-os produtivos e característicos da singularidade de sua poética.

\section{Abstract}

From a comprehension of poetry as something that exists in the world, and not just at the body of the poem, Murilo Mendes had been able to expand the reach of his aesthetics experimentation, including manifestations, forms and perspectives of various types of art. This text tries to analyze some of the meaning relations between the poet's work - especially his poetry work -, painting and literature, from the contacts in which Murilo, at one side, establish his most important influences, and on the other side, assumes several procedures, making them productive and distinctive of his own poetics. 